\title{
Correction to: The structure of Chinese beginning online instructors' competencies: evidence from Bayesian factor analysis
}

\author{
Yixi Wang ${ }^{1}$ Yang Wang ${ }^{2}$ (D) David Stein ${ }^{3} \cdot$ Qingtang Liu $^{4} \cdot$ Wenli Chen $^{5}$
}

Published online: 27 May 2021

(C) Beijing Normal University 2021

\section{Correction to: J. Comput. Educ. https://doi.org/10.1007/s40692-021-00186-9}

In the original publication of this paper, the order of first and second author has been swapped. The correct author order and the revised affiliation are provided in this Correction. Also the affiliation of first author should read as: National Institute of Educational Sciences, Beijing, China.

The original article has been corrected.

Publisher's Note Springer Nature remains neutral with regard to jurisdictional claims in published maps and institutional affiliations.

The original article can be found online at https://doi.org/10.1007/s40692-021-00186-9.

\section{Yang Wang}

wangyang@nnu.edu.cn

1 National Institute of Educational Sciences, Beijing, China

2 School of Educational Science, Nanjing Normal University, Xianyin North Road, Qixia District, Nanjing 210046, China

3 Ohio State University, Coulmbus, OH, USA

4 Central China Normal University, Wuhan, China

5 Nanyang Technological University, Singapore, Singapore 